\title{
Propagation and coalescence of en-echelon cracks under a far-field tensile stress regime: An experimental study
}

\author{
Nilanjana Ghosh*, Kalyanbrata Hatui and Anupam Chattopadhyay \\ Department of Geology, University of Delhi, Delhi 110 007, India. \\ *Corresponding author. e-mail: ng1704@gmail.com
}

MS received 27 July 2017; revised 27 February 2018; accepted 6 May 2018; published online 16 January 2019

Experiments were carried out to observe the variation in propagation and linkage of parallel en-echelon cracks with varying orientation of the crack array and different relative position of the cracks within the array in an extensional regime. Two-layered analogue model, with a basal layer of pitch overlain by a layer of kaolin paste was used in the experiments. En-echelon cracks were pre-cut within the kaolin layer maintaining specific geometrical parameters of the cracks (e.g., length, centre spacing, separation) in such a manner that there was a weak (though not negligible) local tip-induced stress favouring curvature of adjacent crack tips towards one another. The results obtained were matched with natural pattern of linkage of veins, rift basins and spreading ridges, as described in the relevant literature. The experimental results showed that the final pattern of linkage between the cracks was a result of initial deflection of crack tip from its plane due to combined effect of local and far-field stress. When the deflection of tip from the crack plane was between $0^{\circ}$ to $45^{\circ}$, a 'tip to wall' linkage took place between adjacent cracks isolating a rhombohedral area in the interaction zone. The resultant structure could be geometrically comparable to a micro-plate-like structure isolated due to linkage of ridge segments initially forming an overlapping spreading centre (OSC). When the deflection of tip from the crack plane was greater than $45^{\circ}$, a 'tip to tip' linkage between adjacent cracks took place resulting in a structure similar to a transform fault between spreading ridges and or rift basins. When effect of the remote stress opposed the tip induced stress, no linkage took place between the adjacent cracks, and finally the tips propagated straight along a plane perpendicular to the remote extension direction.

Keywords. En-echelon cracks; far-field stress; local tip induced stress; overlapping spreading centre; transform fault.

\section{Introduction}

En-echelon cracks are common in rocks deformed in the brittle-ductile regime. They are believed to develop initially as tension cracks as a manifestation of interaction between the far-field and the local stress fields (Hancock 1972). Arrays of en-echelon cracks occur in rocks at various scales from a few millimeters to several kilometers.
Such structures are common in different geological settings like rift basins, releasing bends, restraining bends, shear zones etc., forming step-like arrays of veins, joints and dykes. Large scale faults also show numerous non-collinear, parallel, step-like faults. Oceanic ridge segments also initially resemble isolated en-echelon cracks (e.g., the oceanic ridges along East Pacific Rise as described by Macdonald and Fox 1983). Even rift segments initially occur 
as an array of small faults with 'in-line' or stepped geometry. Gradually in the process of evolution of rift zone the segments grow, interact and are linked to form larger structures (e.g., the East African Rift system as described by Nelson et al. 1992).

In a homogeneous medium, fracture propagation is usually visualized as co-planar crack propagation. However, in natural system there is evidence of cracks showing curvilinear crack tip propagation. Earlier workers modeled such curved crack propagation based on theoretical (Segall and Pollard 1980; Pollard et al. 1982; Pollard and Aydin 1984; Nicholson and Pollard 1985; Cox and Scholz 1988; Olson and Pollard 1991; Gudmundsson et al. 1993; Lebel and Mountjoy 1995; Willemse et al. 1996; Willemse 1997; Maerten et al. 1999) and experimental (Thomas and Pollard 1993; Mandal 1995; An and Sammis 1996; Mauduit and Dauteuil 1996; An 1998; Acocella et al. 1999; Basile and Brun 1999; Schreurs et al. 1999) results of interaction of several arrays of cracks. The most important factors which affect the behavior of the en-echelon cracks are (1) the geometry of arrangement (e.g., separation, overlap) of the cracks, (2) the type of loading, i.e., either mode I (displacement perpendicular to the crack wall), or mode II (slip parallel to the crack wall) or mixed mode I and II, and (3) the relative influence of far-field stress (stress acting uniformly all over the area concerned) and local tip-induced stress (stress generated due to influence of adjacent crack tip). The findings of the earlier workers focusing on the above mentioned factors are summarized below.

A single, isolated crack tip usually propagates laterally straight along its plane within a homogeneous medium under the influence of far-field stress. If another crack is present nearby, the tips of the cracks start influencing one another. Under mode I loading when the overlap is negative (underlap) the tips initially diverge slightly from each other. From zero to increasing positive overlap the tips try to converge towards each other (Swain and Hagan 1978; Pollard et al. 1982; Nicholson and Pollard 1985; Sempere and Macdonald 1986; Du and Aydin 1991; Fleck 1991; Thomas and Pollard 1993; and many others) (figure 1a). However, if the far-field stress dominates over local tip-induced stress, the crack tips continue to propagate straight (Olson and Pollard 1989). Sense of stepping does not matter in case of mode I loading. There is always a critical range of spacing between the individual cracks within an array below which individual cracks coalesce with each other to form a

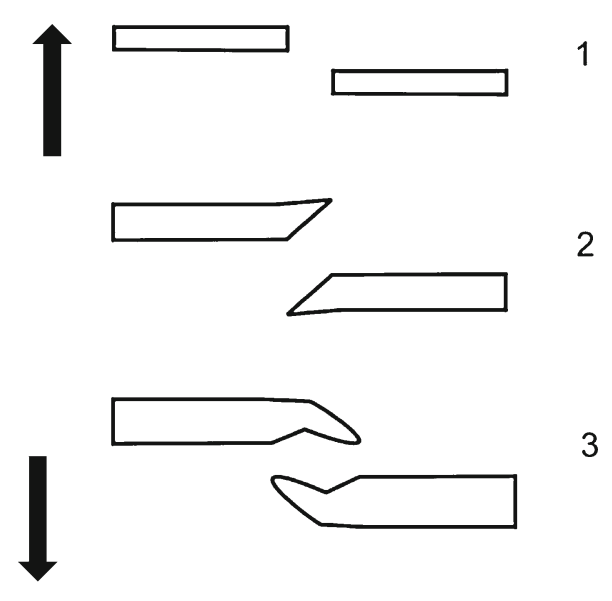

(a)

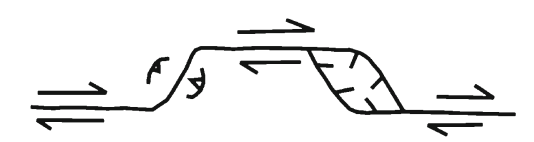

(b)

Figure 1. Schematic diagrams of behavior of en-echelon cracks under different deformational conditions. (a) Successive stages of propagation of cracks under mode I loading, where local stress is greater than remote stress (1) initial arrangement of en-echelon cracks with little underlap, (2) slight divergence of the tips before starting of overlap, and (3) convergence of tips as overlap started. (b) Under layer parallel dextral shear-extensional bend was formed between the tips of right-stepping cracks and compressional bend was formed between the tips of the left-stepping cracks.

single fracture zone and above which cracks do not mutually interact with each other and form a sigmoidal shape (Mandal 1995). Ramsay and Lisle (2000, pp. 766-768) have used finite element method to investigate the stress distribution in complex cracks. For mode II loading, releasing (extensional) bends are formed for dextral shear and right-stepping (or sinistral shear and leftstepping) arrangement of cracks, whereas restraining (compressional) bends are formed for dextral shear and left-stepping (or sinistral shear or rightstepping) arrangement of the cracks (Segall and Pollard 1980) (figure 1b).

In comparison to mode I and mode II loading, relatively fewer works have been done on behavior of en-echelon cracks under mixed mode I and II loading in the geological context. For example, Crider (2001) proposed a numerical model to show a systematic relationship between en-echelon step sense, oblique slip sense and the position of linking faults, and compared the results with the map patterns of normal fault linkage near Summer Lake, Oregon. Bellahsen and Daniel (2005) 
demonstrated experimentally that if the pre-existing discontinuities are at low angle to the extension direction, they get reactivated and accommodate majority of the extension. When the pre-existing discontinuities are at a high angle to the extension direction, they get reactivated under extension but act as relay faults to the newly formed faults formed perpendicular to the extension direction. Moir et al. (2010) first gave a numerical simulation of the temporal and spatial evolution of fault linkage structures from more than 20 pre-existing joints, the initial positions of which were based on field observation. They showed that within a far-field compressive stress the fault zone geometry is governed by the interaction between the neighboring joints and orientation of the initial joint pattern with respect to the far-field stress.

Results of the experimental studies on behaviour of en-echelon cracks within an array in an extensional regime have been used to interpret the pattern of interaction and linkage of oceanic ridges by many workers (Tentler 2003a, b; Acocella 2008; Tentler and Acocella 2010, etc.). They have proposed that only simple geometrical arrangement of en-echelon cracks (excluding the influence of other factors such as magmatic activity, thermal stability, occurrence of pre-existing anisotropy, etc.) may control the linkage pattern of the ridge segments. Therefore, formation of two end members of the various interaction patterns of ridge segments (either overlapping spreading centre (OSC) or transform faults) is partially controlled by the geometry of their initial arrangement. Tentler (2003a,b) proposed three different types of crack tip coalescence pattern based on the variation in overlap, separation, $\alpha$ (the inclination angle between two fractures), and $\beta$ (the inclination angle between the fracture tip and the other fracture towards which it is propagating). Type 1 (tip to tip coalescence) takes place when there is negative overlap, small offset and very small $\alpha$ and $\beta$. Type 2 (double tip to sidewall coalescence) occurs when there is small positive overlap, a small offset and a small $\alpha$ inclination. Type 3 (single tip to sidewall coalescence) takes place when there is a large positive overlap, relatively small offset and a pronounced $\alpha$ inclination. Acocella (2008) proposed from natural examples that a simple length $(L) /$ separation $(S)$ ratio between the interacting ridges will control the formation of either OSC or transform faults.

Tentler and Acocella (2010) have shown, by their experiments under orthogonal extension, that oblique extension is not required for the formation of OSC (in contradiction to Katz et al. (2005), who had earlier shown that OSC develops predominantly on obliquely spreading ridges with the ridge striking at $45^{\circ}$ ). Tentler and Acocella (2010) concluded that increase in separation favours development of new straight fractures at high angle to the parent fractures resembling transform like structures. Zwaan et al. (2016) studied experimentally, and by numerical modeling, the effect of oblique extension and the offset between the initial heterogeneities on continental rift interaction. Their study revealed that increasing extension obliquity favors narrow rifts and hard linkage (actual linkage by discrete fault) of rift segments whereas orthogonal extension favours soft linkage (distributed zone of deformation between the rift segments without any discrete fault) and wide rifts. Zwaan and Schreurs (2017) showed experimentally that dextral oblique extension favors hard linkage of right-stepping cracks, whereas sinistral oblique extension favors hard linkage of left-stepping cracks and vice-versa.

Despite all the above mentioned works, till now there is no definitive experimental work that can establish the control of the combined effect of local and far-field stress (which in turn varies with the orientation and arrangement of cracks) in the propagation and linkage of the cracks in an extensional regime. Keeping our focus on this problem, we have carried out experiments to study the variation in propagation, dilation, interaction and linkage of en-echelon cracks due to the variation in their orientation and the relative position between the adjacent cracks within an extensional regime. With change in the orientation of cracks, the sense and amount of shear component of the far-field stress on the crack plane is changed and this, along with the relative position of the adjacent crack, either helps or inhibits the linkage of cracks. The results of these experiments are well matched with natural linkage of veins and/or ridge segments, as discussed later.

\section{Experimental setup}

\subsection{Deformation rig}

The deformation rig, as shown in figure 2, consists primarily of a base plate and two movable motor-driven metal pistons. A pair of rectangular wooden blocks was attached to the moving pistons 


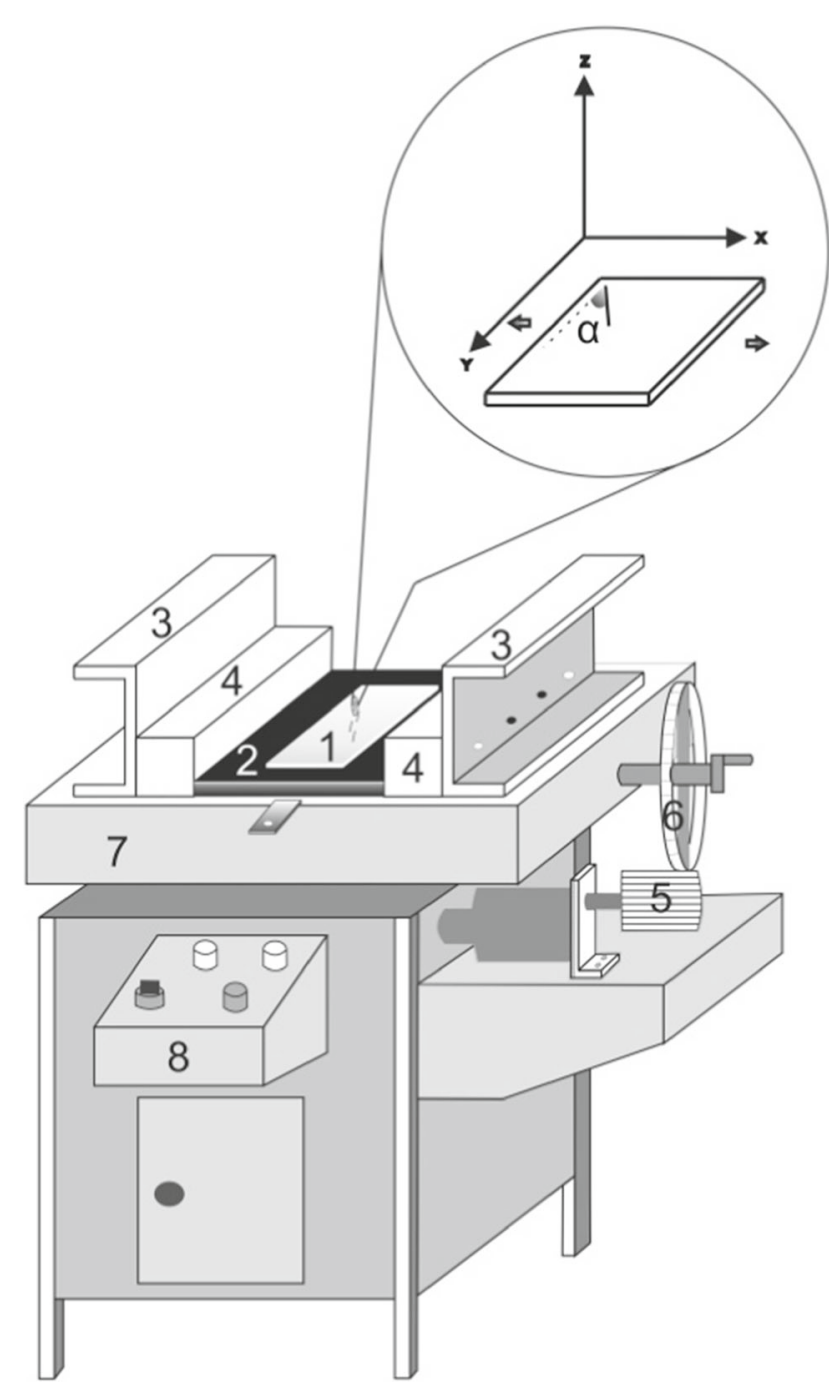

Figure 2. Sketch of deformation rig showing different components. 1 = kaolin layer, $2=$ pitch block, $3=$ moving pistons, $4=$ rectangular wooden blocks, $5=$ motor, $6=$ gear, $7=$ base plate, $8=$ electrical switch board. Inset showing the model with stretching axes. Extension is along $X$ axis and contraction is along $Z$ axis.

between which the soft model was kept. The pistons along with the wooden blocks were capable to move inward or outward at a rate of $\approx 2 \mathrm{~mm} \mathrm{~min}^{-1}$ producing either compression or extension of the model, respectively. For our experimental requirement, we have only used the extensional set up of the metal pistons.

\subsection{Modelling technique}

Analogue models were made by using two different materials: pitch (bitumen, purchased from Indian Oil Limited) and kaolin (of Thomas Baker brand). A rectangular block of pitch of dimension $(25 \times 15 \times 3 \mathrm{~cm})$ was made, upon which a kaolin paste (kaolin powder mixed with water in 3:1 ratio by volume) layer of dimension $(21 \times$ $11 \times 0.5 \mathrm{~cm})$ was placed. The model was placed between two movable pistons of the deformation rig. The two opposite walls of the pitch block were firmly attached with the wooden blocks by applying a thin coating of liquefied pitch and allowing it to solidify. The model was extended along one direction $(X)$ by moving the pistons away from each other. The dimension of the model along $Y$ direction remained fixed, and thinning took place along vertical $(Z)$ direction. Thus, the deformation took place more or less under a plane strain condition (figure 2). Parallel cuts, each of $3 \mathrm{~cm}$ length $(b)$ and negligible thickness $(<0.05 \mathrm{~cm})$, were induced within the kaolin layer maintaining either a left-stepping or a right stepping enechelon arrangement. The separation $(s)$ between the cuts was kept at $0.5 \mathrm{~cm}$ (taking into consideration that the separation should not be too small so that they could merge with each other while initially putting them or soon after the initiation of deformation, and should not be so large that they have no influence upon one another). The centre spacing $(k)$ between the cracks was $3 \mathrm{~cm}$ which makes the overlap (o) zero (figure 3 ). The parameters were fixed at these values (following figure 5b of Pollard and Aydin 1984) to ensure that with the onset of deformation the local tip induced stress (weak but not negligible) always favoured the curvature of adjacent crack tip towards one another. Under this set up, different series of experiments were done by changing the value of obliquity $\alpha$ (the angle between the crack and the zone margin, measured positive anticlockwise and negative clockwise $)=0^{\circ}, \pm 15^{\circ}, \pm 30^{\circ}$ (figure 3). For each value of $\alpha$ two different experiments were done by keeping the relative positions of cracks either left-stepping or right-stepping (figure 4).

For positive value of $\alpha$, the sense of shear induced by the far-field stress on the cracks was dextral and for negative $\alpha$ it was sinistral (figure 4). Dextral shear favoured the tips of the right-stepping cracks to curve towards each other and the tips of the left-stepping cracks to curve away from each other. Sinistral shear, on the other hand, curved the tips of left-laterally arranged cracks towards each other and the tips of right-stepping cracks away from each other (figure 4). For convenience of description we have only described the results of positive value of $\alpha$ for both the arrangements. For negative values of $\alpha$, the results of left-stepping arrangement 

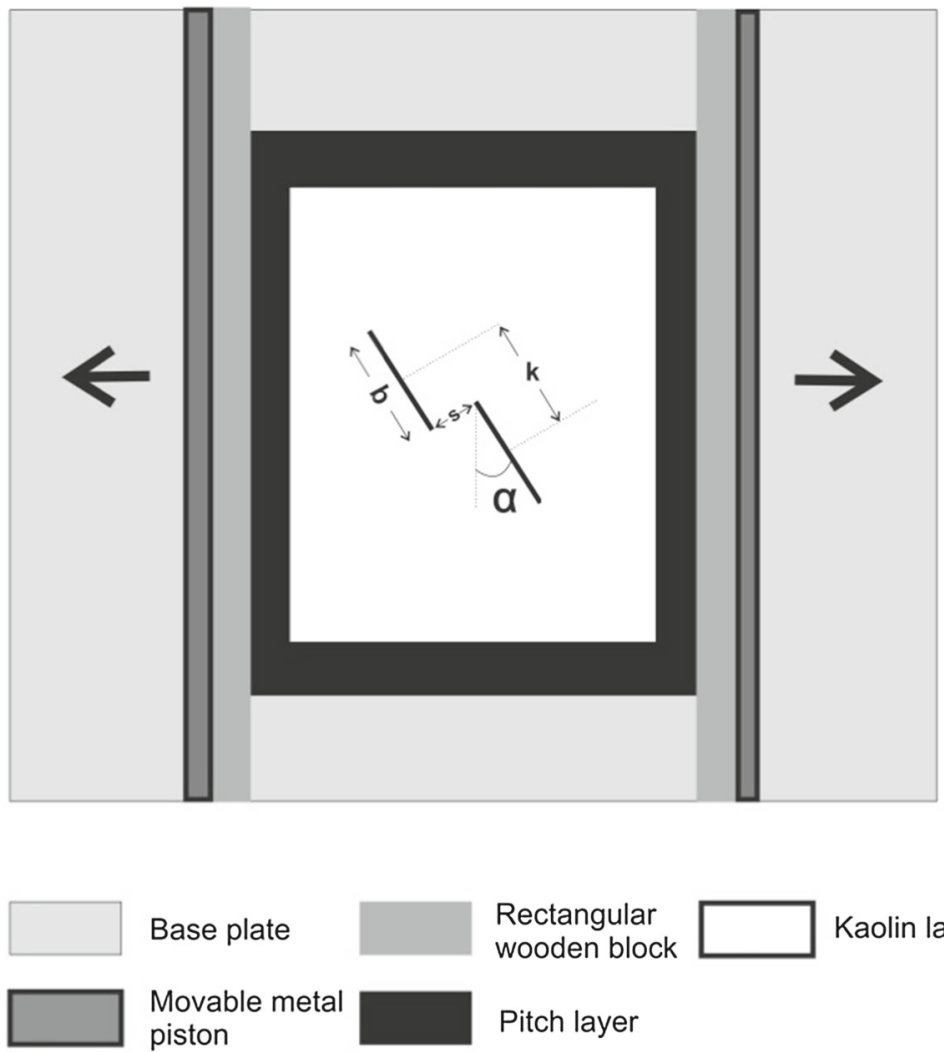

Base plate
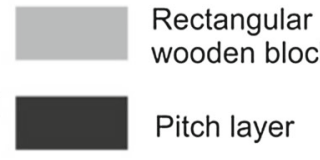
wooden block

Kaolin layer

Movable metal piston

Pitch layer

Figure 3. Sketch showing the plan view of the model set within the deformation rig. The parameters are $b=$ crack length, $k=$ spacing between the centers measured parallel to the cracks, $s=$ separation between the cracks, $\alpha=$ angle of the crack with the zone margin.

was same as the right-stepping arrangement of the positive $\alpha$ and vice versa.

Each experiment was conducted three times to get accurate observations and to reduce the magnitude of errors. Photographs of the model at successive stages of deformation were taken at regular intervals. The length of the model was measured at each stage and the longitudinal strain at that stage was calculated as the ratio of change in length to the initial length. We changed the value of $\alpha$ to simulate mode I and II loading. For example, $\alpha=0^{\circ}$ simulated the mode I loading, whereas increasing the value of $\alpha$ induced a combination of mode I and II loading (figure 3).

\subsection{Model scaling}

To study the large-scale deformation systems, the laboratory models should be scaled to their natural analogues, so that the model and its natural prototype remain geometrically, kinematically and dynamically similar (Hubbert 1937; Ramberg 1975; Chattopadhyay and Mandal 2002; Ghosh et al.
2014). In the present case, we have used viscous models (pitch) under slow strain rate $\left(\sim 10^{-4} \mathrm{~s}^{-1}\right)$ (calculated using the method described in Ghosh et al. 2014). Therefore, we can assume negligible inertial forces for the present case following Hubert's argument that in case of very slowly moving viscous models, the forces due to inertia can be neglected without causing significant error. When we compare the model viscosity ratio, which is calculated from the fundamental model ratios $(\zeta=$ $\delta \lambda \tau=1.9 \times 10^{-16}$; where $\delta, \lambda$ and $\tau$ are model ratios of density, length and time ratio, respectively) with the actual model viscosity ratio found in its natural analogue (e.g., $\left.\zeta=0.51 \times 10^{-16}\right)$, they are found to be within the same order of magnitude (table 1 ) (modified after Chattopadhyay and Mandal 2002; Ghosh et al. 2014). Thus, our models could achieve approximate dynamic scaling, and the results of our experiments can hence be applied to natural situations. Although wet kaolin is inappropriate for scaled modeling of ductile deformation, it is commonly used as analogue material for simulating brittle fractures (e.g., Tchalenko 1970). 


\section{Experimental observations}

For mode I loading, the observations from both right and left-stepping cracks are described together as they behaved similarly. However, for mixed mode loading, right and left-stepping cracks show contrasting pattern of propagation and so their observations were described separately.

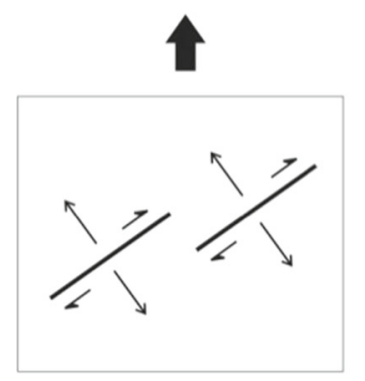

(a)

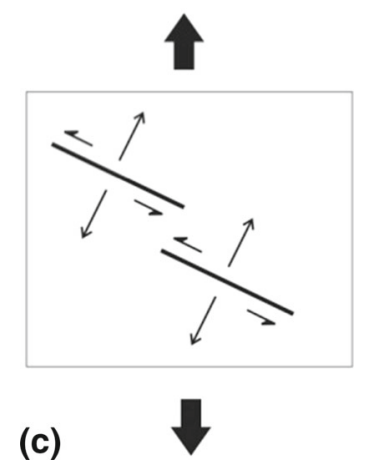

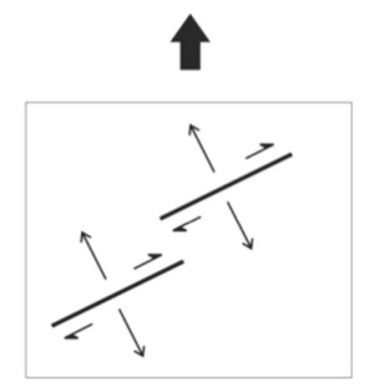

(b)

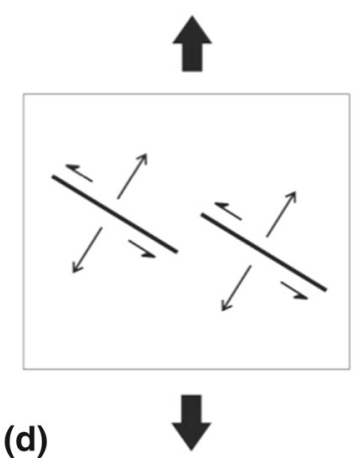

(d)

Figure 4. Sketch illustrating the effect of remote stress on crack plane. (a) Right-stepping cracks with positive $\alpha$. (b) Left-stepping cracks with positive $\alpha$. (c) Right-stepping with negative $\alpha$. (d) Left-stepping with negative $\alpha$.

\subsection{For $\alpha=0^{\circ}$}

When the crack array was parallel to the boundary of the model the shear component of the farfield stress on crack plane was zero (mode I loading). As a result the left-stepping and the right stepping arrangement behaved as the same. Figure 5(a) shows the initial stage of right-stepping cracks. With increasing deformation the fractures started opening up perpendicular to the wall. The region between the tips took up ductile bending (figure 5b).The pattern of opening up of the outer wall (the wall away from the adjacent crack) and the inner wall (the wall towards the adjacent crack) were different. The outer wall opened up in a straight line along the entire length of the crack up to the tip, whereas the opening up of the inner wall was maximum at the centre and gradually decreased towards the tip. With continuous deformation at a bulk longitudinal strain of 0.03 , along with opening up, the tips of the fractures also started propagating laterally along its plane. The adjacent fractures started overlapping each other. Near the tip the outer wall was curved from the crack plane at $45^{\circ}$, whereas the inner wall propagated straight parallel to the crack (figure 5c). With continued deformation the tip of one fracture and the outer wall of the adjacent fracture continued to come closer to each other and finally at a longitudinal strain of 0.34 they joined isolating a rhombohedral bridge area (figure $5 \mathrm{~d}$ ). The pattern of propagation, opening up and linkage between the adjacent cracks were similar for both the arrangements (figures 5 and 6). Figure 5(e) shows the schematic representation of successive stages of propagation and linkage of right-stepping cracks.

Table 1. Model parameters and scaling ratio (adapted and modified from Chattopadhyay and Mandal 2002; Ghosh et al. 2014).

\begin{tabular}{llll}
\hline Physical parameters & \multicolumn{1}{c}{ Model $(\mathrm{pitch})$} & \multicolumn{1}{c}{ Nature } & Model scaling ratio \\
\hline 1. Acceleration due to gravity $(g)$ & $g_{\mathrm{m}}=9.81 \mathrm{~m} \mathrm{~s}^{-2}$ & $g_{\mathrm{n}}=9.81 \mathrm{~m} \mathrm{~s}^{-2}$ & $g_{\mathrm{m}} / g_{\mathrm{n}}=1$ \\
2. Co-efficient of viscosity & $n_{\mathrm{m}}=1.5 \times 10^{5} \mathrm{~Pa} \mathrm{~s}^{\mathrm{c}}$ & $n_{\mathrm{n}}=2.9 \times 10^{21} \mathrm{~Pa} \mathrm{~s}^{\mathrm{d}}$ & $n=0.51 \times 10^{-16}$ \\
3. Length & $l_{\mathrm{m}}=15 \mathrm{~cm}$ & $l_{\mathrm{n}}=25 \mathrm{~km}$ & $k=l_{\mathrm{m}} / l_{\mathrm{n}}=0.6 \times 10^{-5}$ \\
4. Rate of shortening & $t_{\mathrm{m}}=2 \mathrm{~mm} \mathrm{m^{-1 }}$ & $t_{\mathrm{n}}=1 \mathrm{~cm} \mathrm{year}^{-1 \mathrm{a}}$ & $s=7.2 \times 10^{-11}$ \\
5. Density & $d_{\mathrm{m}}=1.15 \mathrm{gm} \mathrm{cm}^{-3}$ & $d_{\mathrm{n}}=2.6 \mathrm{gm} \mathrm{cm}^{-3 \mathrm{~b}}$ & $d=d_{\mathrm{m}} / d_{\mathrm{n}}=0.45$ \\
\hline
\end{tabular}

${ }^{\mathrm{a}}$ From Cotton and Koyi (2000).

${ }^{\mathrm{b}}$ Averaged from the density of granites and that of sedimentary rocks (after Hubbert 1937; Cotton and Koyi 2000).

${ }^{\mathrm{c}}$ Viscosity data from Jaeger (1969).

${ }^{\mathrm{d}}$ Data from Haskell (cited in Hubbert 1937). 


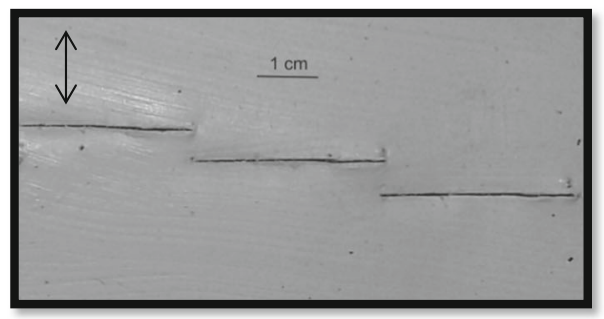

(a)

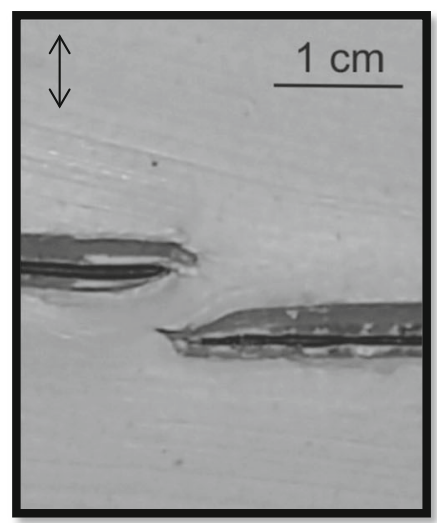

(c)

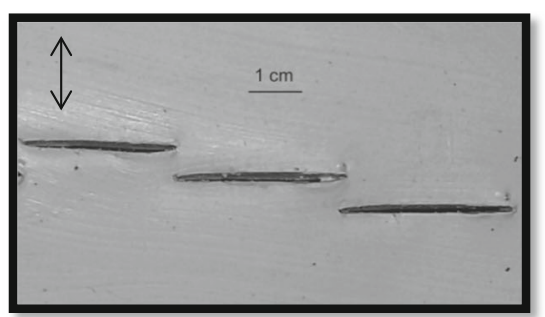

(b)

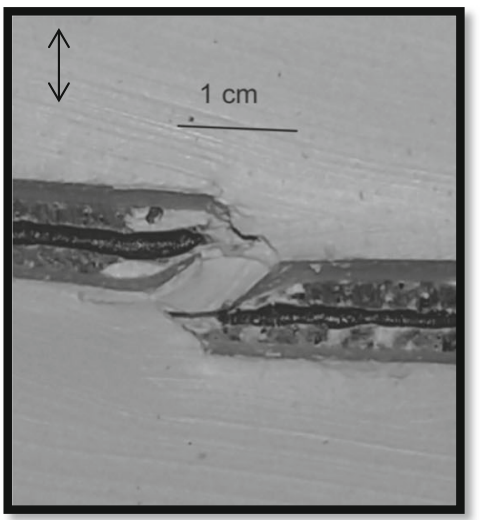

(d)

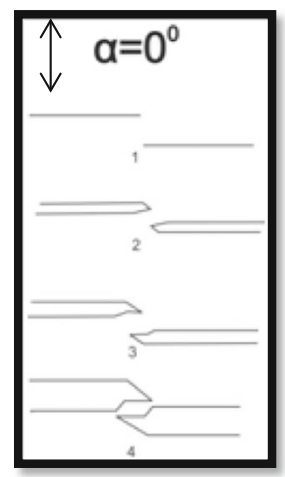

(e)

Figure 5. (a) Initial right-stepping arrangement for $\alpha=0^{\circ}$. (b) Dilation started without any lateral propagation. (c) Tips started propagating along straight line. Curvatures of outer wall and inner wall were different. (d) Linkage of tip with the outer wall of the adjacent crack isolating a domain in between the tips. (e) Schematic representation of propagation and linkage of en-echelon cracks when $\alpha=0^{\circ}$.

\subsection{For $\alpha=15^{\circ}$, right-stepping arrangement of cracks}

Figure 7(a) shows the initial arrangement of cracks. With onset of deformation the fractures opened up along a direction parallel to the remote extension. Soon after a longitudinal strain of 0.1 (deformed model length $15.5 \mathrm{~cm}$ ), tips of the adjacent cracks smoothly curved towards each other at an angle of $35^{\circ}$ with the plane of the crack, with little or no dilation. With continued deformation it was noticed that the angle of bending of outer wall at tip became much higher (about $60^{\circ}$ ) than that of inner wall. Upon further deformation, at a longitudinal strain of 0.3 (deformed model length $19.5 \mathrm{~cm}$ ), the tips of the cracks joined with the wall of the adjacent cracks almost isolating a rhombohedral bridge area between them (figure $7 \mathrm{~b}$ ). 


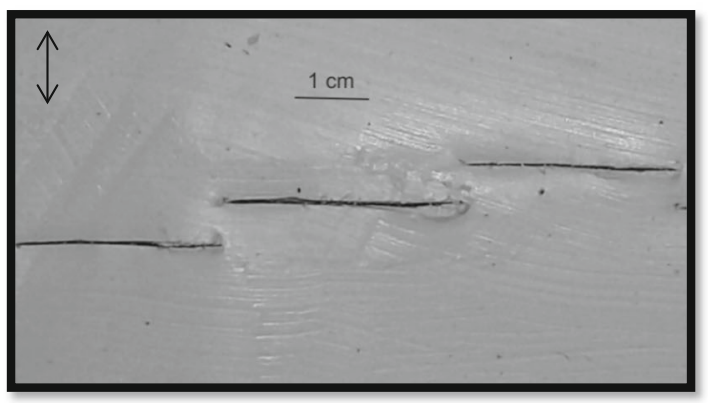

(a)

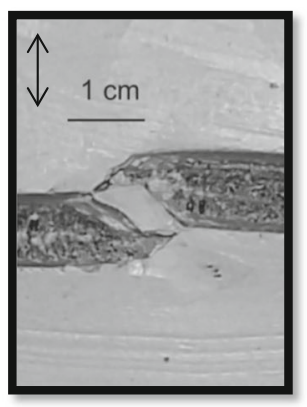

(b)

Figure 6. (a) Initial left-stepping arrangement for $\alpha=0^{\circ}$. (b) Linkage of tip with the outer wall of the adjacent crack isolating a rhombohedral domain in between the tips.

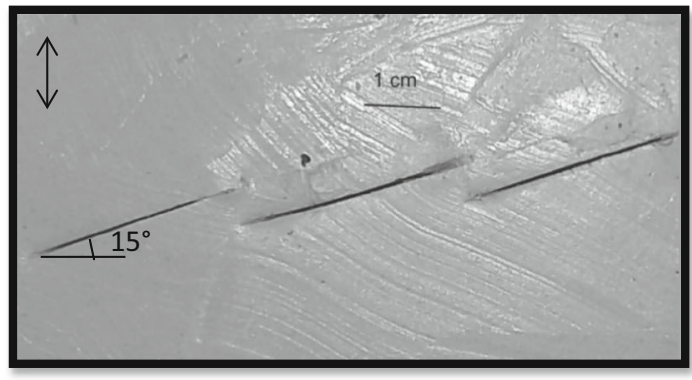

(a)

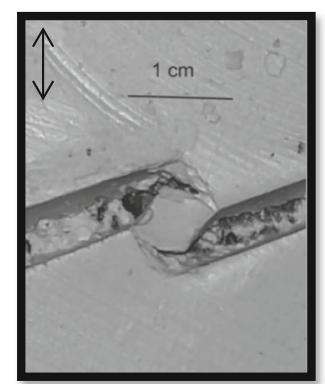

(b)

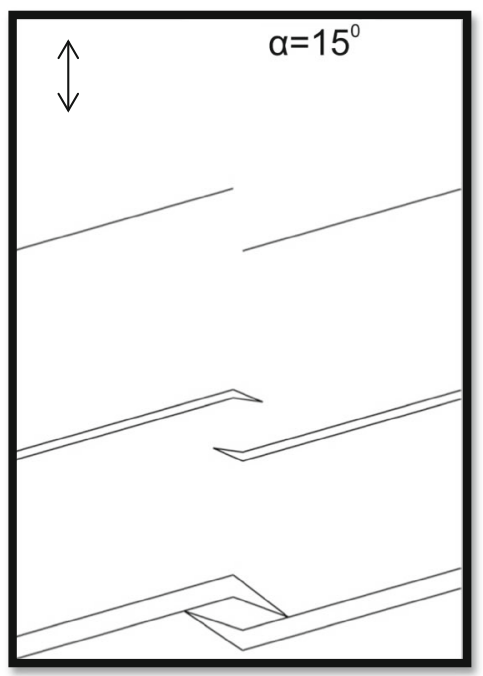

(c)

Figure 7. (a) Initial right-stepping arrangement for $\alpha=15^{\circ}$. (b) Linkage of tip with the outer wall of the adjacent crack isolating a domain in between the tips. The domain is rotated w.r.t the crack plane. (c) Schematic drawing of propagation and linkage of en-echelon cracks for $\alpha=15^{\circ}$.

A schematic representation of successive stages of propagation and linkage of cracks is shown in figure $7(\mathrm{c})$.

\subsection{For $\alpha=15^{\circ}$, left-stepping arrangement of cracks}

Figure 8(a) shows the initial arrangement of cracks. With ongoing deformation the fractures started to open up initially with no lateral propagation. The opening up was maximum at the center and gradually decreased at the tips. As a result they took an eye shape with bulged central part and tapered tips. After a bulk longitudinal strain of 0.3 (deformed model length $19.5 \mathrm{~cm}$ ), at a maximum dilation of $0.5 \mathrm{~cm}$, a tiny extensional fracture developed at the tip from the terminal point of the outer wall and was oriented along the plane 


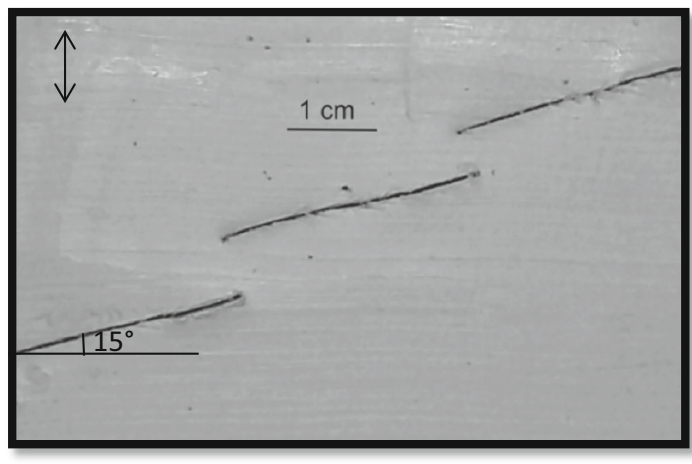

(a)
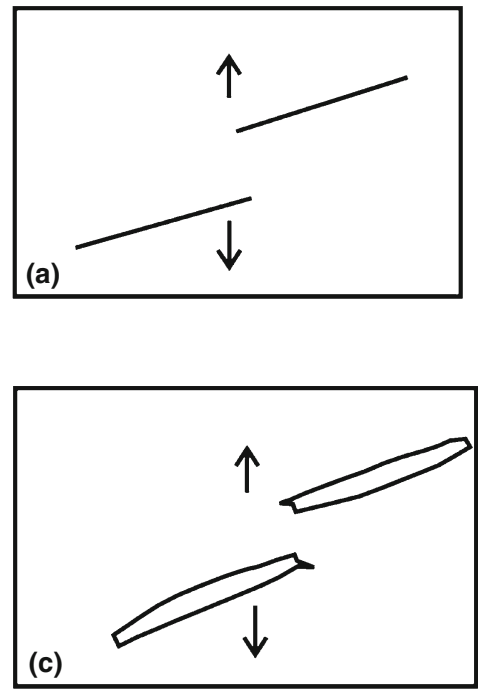

(c)

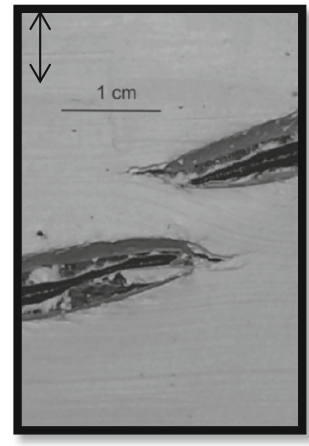

(b)
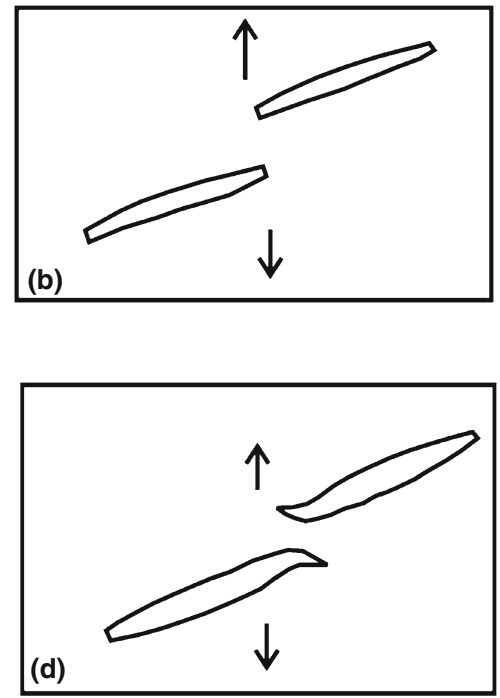

Figure 8. (a) Initial left-stepping arrangement for $\alpha=15^{\circ}$. (b) Tips propagated straight along the plane perpendicular to the extension direction. (c) Schematic representation of successive stages of the propagation of fractures.

perpendicular to the remote extension direction. The angle between the crack plane and the new fracture was about $165^{\circ}$. With increasing deformation the pointed tip of this fracture continued to propagate along the plane perpendicular to the remote extension direction (figure 8b). Figure 8(c) shows the schematic representation of successive stages of crack propagation.

\subsection{For $\alpha=30^{\circ}$, right-stepping arrangement of cracks}

Initially the fractures were arranged as shown in the figure $9(\mathrm{a})$. After the onset of deformation, at a longitudinal strain of 0.06, (corresponding to a deformed length of $15.9 \mathrm{~cm}$ ) tips of the adjacent fractures sharply curved towards each other making an angle of $50^{\circ}$ with the fracture wall. Dilation of the cracks was almost negligible (figure $9 \mathrm{~b}$ ).
With continued deformation the outer wall moved away and the deviation of outer wall at the tip became almost $90^{\circ}$ (figure $9 \mathrm{c}$ and d). Inner wall remained at the same place. At a longitudinal strain of 0.2 , the tip of one fracture joined the tip of the adjacent fracture producing a continuous single $Z$-shaped fracture (figure 9e). Figure 9 (f) shows the schematic representation of the successive stages of crack propagation and linkage.

\subsection{For $\alpha=30^{\circ}$, left-stepping arrangement of cracks}

Cracks which were initially arranged as shown in figure 10(a), opened up with an elliptical shape in cross section, with tapering edges, and a dilated central part. Gradually with increasing deformation, at a longitudinal strain of 0.2 (corresponding to a deformed length of $18 \mathrm{~cm}$ ) and at a 


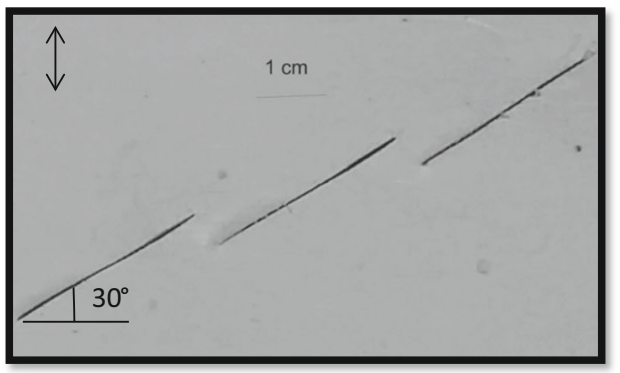

(a)

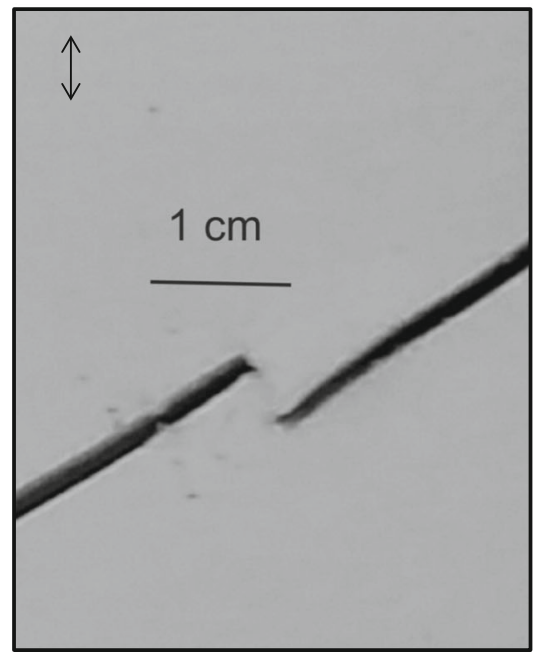

(c)

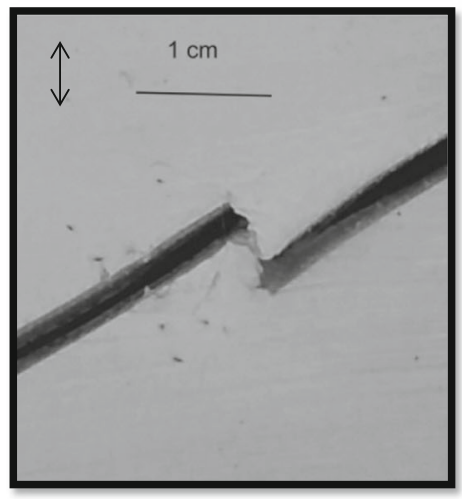

(e)

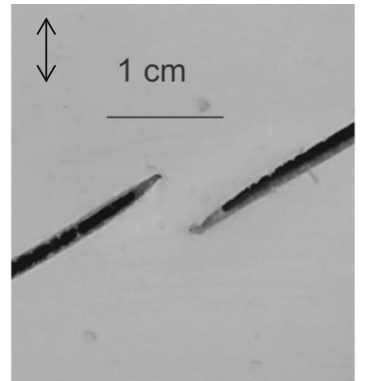

(b)

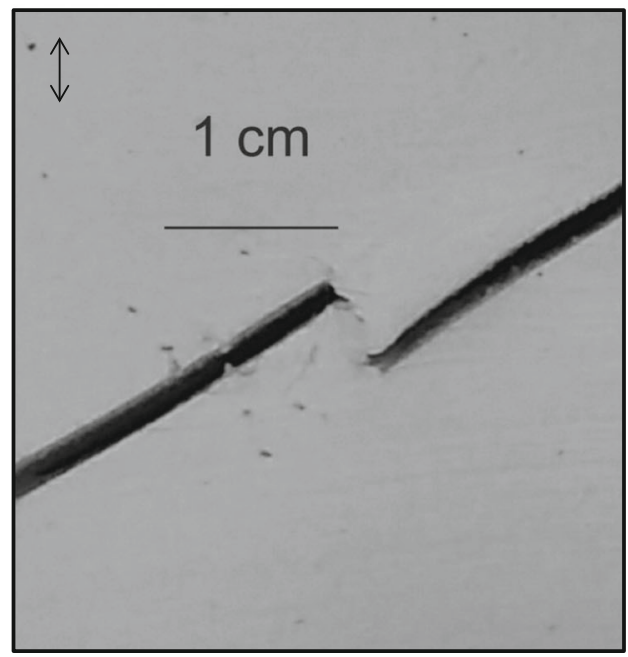

(d)

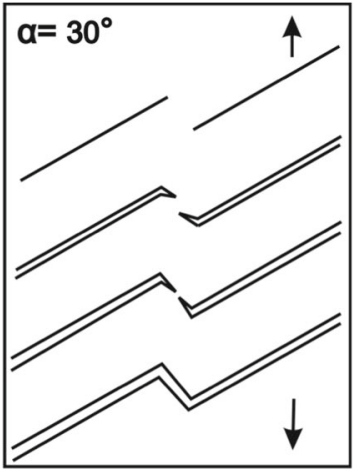

(f)

Figure 9. (a) Initial right-stepping arrangement for $\alpha=30^{\circ}$. (b) Stage 2 of crack propagation showing incipient tip propagation at a direction around $50^{\circ}$ with the crack plane. (c) Stage 3 of crack propagation showing angle of curvature of the outer wall higher than that of inner wall. (d) Stage 4 of crack propagation showing curvature of outer wall is at $90^{\circ}$ with the crack plane. (e) Final stage showing tip to tip linkage between adjacent cracks. (f) Schematic representation of the successive stages of the propagation of the fractures.

dilation of 0.3 , a tiny extensional fracture developed at the tip from the terminal point of the outer wall and was oriented along the plane perpendicular to the remote extension direction. As a result the angle between the fracture tip and wall was around $150^{\circ}$ (figure $10 \mathrm{~b}$ ). With increasing deformation the pointed tip of this fracture widened up and continued to propagate along the plane perpendicular to the remote extension direction. The pattern was similar as shown in figure $8(\mathrm{c})$. Only the angle between the crack plane and the plane of propagation of tip was different. In both these cases, there was no hard linkage between the adjacent cracks. 


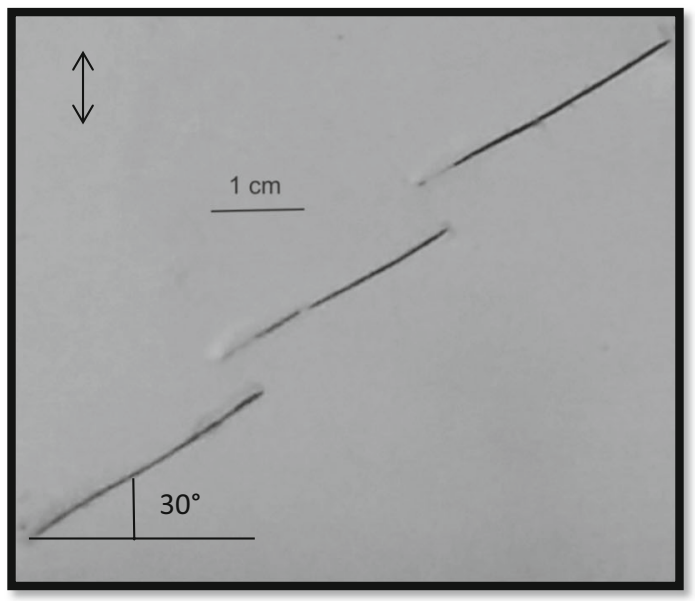

(a)

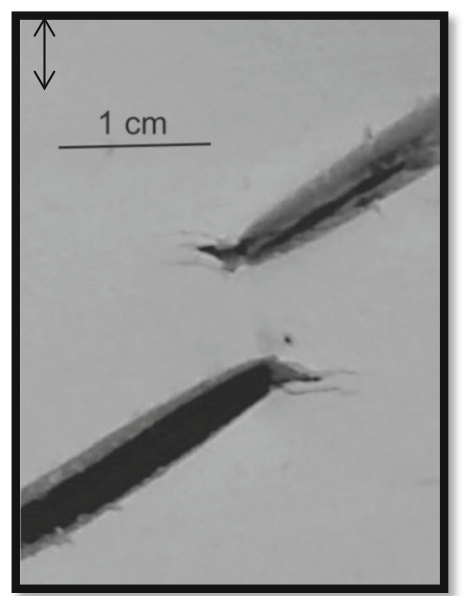

(b)
Figure 10. (a) Initial left-stepping arrangement for $\alpha=30^{\circ}$ a plane perpendicular to the orthogonal extension.

\section{Variation in dilation of cracks}

Maximum dilation (distance between the two walls of the crack measured perpendicular to the crack plane at that point) of the cracks was measured for each set up. Crack length $(b)$ was measured along the crack plane and centre spacing $(k)$ of cracks was measured straight from center to center parallel to the crack plane (figure 11a). For each case an array of 3 cracks was chosen. The dilation and the width of the central crack were measured before the linkage. After linkage the width of the total array was considered and center spacing was taken as the distance between the centers of the 1st and the 3rd crack. Dilation $(\delta)$ was measured perpendicular to the fracture wall at the point at which it was maximum (figure 11b). The value of dilation, normalized by $k(\delta / k)$, were plotted against $b / k$ as shown in figure $11(\mathrm{c})$ ( $b=$ length of the crack, $k=$ center-to-center spacing between the cracks). For $\alpha=0^{\circ}$, maximum dilation was at the center of the crack for both right-stepping and left-stepping arrangement, whereas for $\alpha=15^{\circ}$ and $30^{\circ}$, maximum dilation was near the tip for right-stepping arrangement and at the centre for left-stepping arrangement.

For $\alpha=0^{\circ}$, dilation of the cracks was similar for both left-stepping and right-stepping arrangement of cracks. Initially the cracks dilated a little before any lateral propagation. With the onset of lateral propagation, the overlap between the adjacent cracks started. The pattern of variation of $\delta / k$ with $b / k$ after the beginning of overlap could be divided into two phases. In the 1st phase, even at $2 \%$ of overlap, there was a sharp increase in dilation and the rate of dilation was much higher than the rate of propagation. This pattern continued till the linkage of the cracks. In the 2nd phase (after linkage) the rate of increase in dilation decreased than the rate of propagation (figure 11c, series 1 ).

For $\alpha=15^{\circ}$, the pattern of variation in $\delta / k$ of right-stepping cracks could be divided in three phases. In the 1st phase, when the tip just started propagating along a curved path, dilation was very little. The rate of propagation was higher than the rate of dilation. In the 2 nd phase, after only $0.2 \mathrm{~cm}$ of propagation and $6 \%$ of overlap, there was a sharp increase in the rate of dilation in comparison to the rate of propagation. In the $3 \mathrm{rd}$ phase (after linkage) the rate of increase in dilation decreased than the rate of propagation (figure 11c, series 2). However, for left-stepping cracks, the variation of dilation had only a single phase. Initially there was much increase in dilation as propagation was hindered due to competition between oppositely directed shear component of the far-field stress and the local stress. But as soon as the far-field stress overcame the local stress, the lateral propagation and overlap initiated. The rate of dilation increased much more rapidly than the rate of propagation (figure 11c, series 4).

For $\alpha=30^{\circ}$, initially there was very little dilation for both right-stepping and left-stepping cracks. For right-stepping cracks, the tip started propagating in a curved path and soon got hardlinked with the tip of the adjacent crack. There was no overlap between the adjacent cracks. Rate 

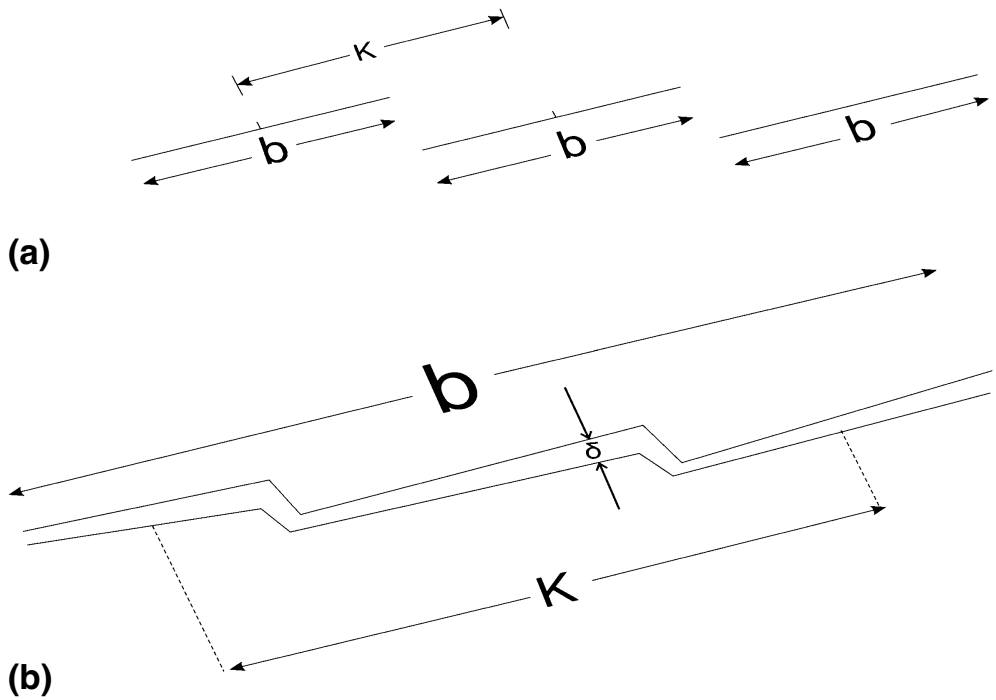

(b)

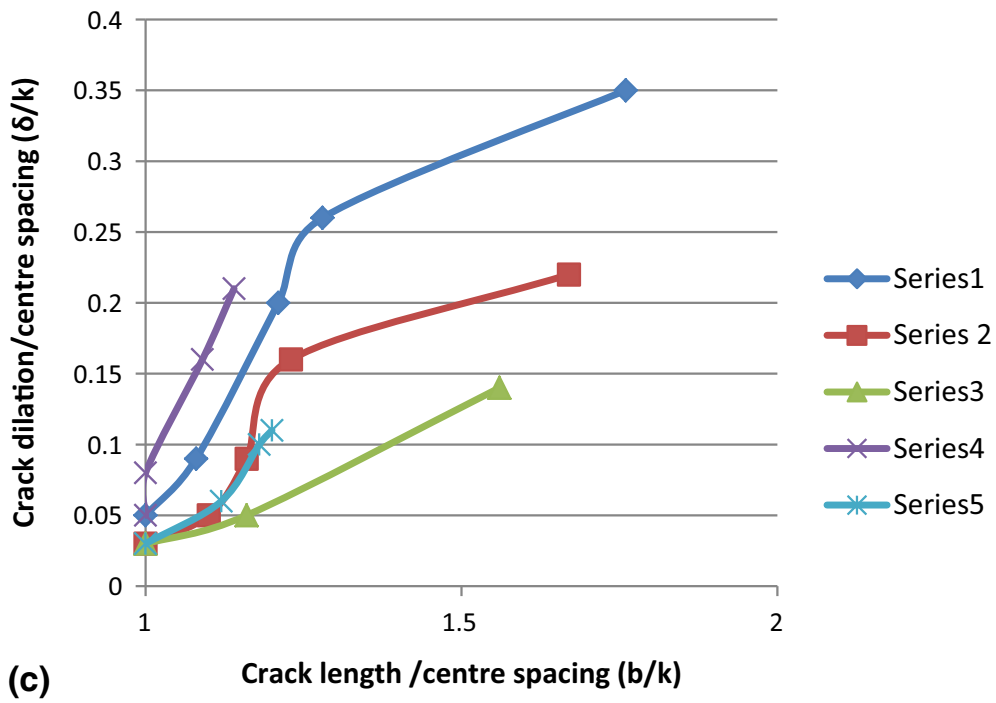

Figure 11. (a) Schematic diagram showing the parameters $b$ and $k$ at initial stage. (b) Schematic diagram showing the parameters $b, k$ and $\delta$ after linkage. (c) Graph showing plot of $\delta / k$ along $Y$ axis against $b / k$ along $X$ axis, where $\delta=\operatorname{dilation}$, $b=$ crack length, $k=$ centre spacing between the cracks measured parallel to the cracks. Legends: Series 1 : For $\alpha=0^{\circ}$ both right and left-stepping arrangement. Series 2: For $\alpha=15^{\circ}$, right-stepping arrangement. Series 3: For $\alpha=30^{\circ}$, right-stepping arrangement. Series 4: For $\alpha=15^{\circ}$, left-stepping arrangement. Series 5: For $\alpha=30^{\circ}$, left-stepping arrangement.

of propagation was higher than the rate of dilation. However, after crack linkage, the rate of increase in dilation was slightly higher than that before linkage (figure 11c, series 3). For left-stepping cracks, immediately after the initiation of propagation the rate of increase in dilation was lower than that of propagation. But soon it became higher than the rate of propagation (figure 11c, series 5).

\section{Discussion}

We have modeled cracks in a nearly homogeneous material, whereas ridge segments and transform faults are associated with a variety of geological parameters. However, a number of earlier workers (e.g., Tentler 2003a,b, 2007; Tentler and Acocella 2010) have modeled the ridge-transform systems as an array of cracks propagating under far-field stress. In experimental modeling (especially in analog models, but also in numerical models) some simple assumptions are necessary, and it is a standard practice. With all other conditions (e.g., magma upwelling rate, heat flow, etc.) remaining same, different ridges/transform segments will behave differently depending on the effect of farfield stress on the crack geometry, as all OSC and/or transform faults initiate as a set of crack 
arrays. Therefore, our models are applicable to the initial stages of development of the ridge-transform systems. Evolved systems will behave differently as more and more inhomogeneity will come into play.

Our experimental results have shown that the amount and orientation of the far-field stress could largely influence the behavior of cracks (dilation/propagation, initial deflection of the crack tip) within an array and thus can influence the pattern of linkage of the cracks. The behavior of those cracks is compared with the propagation and linkage of small scale natural structures like veins and/or dykes or large scale structures like rift basins or ridge segments. Assuming these cracks as representation of initial natural ridge segments (as described by many earlier workers like Macdonald et al. 1984, 1988; Sempere and Macdonald 1986; Grindlay and Fox 1993; Taylor et al. 1994; Gudmundsson 1995; Cowie 1998), variation in the geometrical pattern of their linkage is proposed as one of the reasons of formation of either OSC or transform faults between the ridge segments.

In our experiments, a sharp increase in the rate of dilation relative to the rate of increase in propagation was observed with an increase in overlap between the adjacent cracks. Dilation was increased to accommodate the applied stress as propagation was hindered due to overlapping of the adjacent cracks. This is in accordance with the model proposed by Pollard and Aydin (1984) that en-echelon ridges with small separations enhance the propagation of each other until a slightly overlapped configuration was achieved, beyond which they impede each other's growth.

When the remote tensile stress is perpendicular to the array of cracks (mode I loading), as long as the overall extension is taken up preferentially by dilation of cracks the intermediate area between the tips undergo a progressive distortion (figure 5c). Similar deformation of bridge area due to the dilation of adjacent fractures was earlier analyzed by Ramsay and Lisle (2000) (their figure 31.12B) using finite element method. Almost similar shape of bridge area between naturally occurring calcite veins in limestone was also shown by these authors from Hannenscrifthorn, Wildhorn Nappe (figure 31.13 of Ramsay and Lisle 2000). Even though the arrangement of ridge segments favors the curvature of their adjacent tips towards one another, presence of dominant far-field stress causes them to propagate laterally in a straight path under mode I loading (similar to the theoretical prediction of Olson and Pollard 1989).
With continued deformation, an initial OSC like structure may form, soon followed by a transfer zone isolating a micro-plate like structure, as shown by our experiments.

If the far-field stress is oblique to the array of ridge segments (mixed mode I and II loading), there would be a shear component of remote stress along the ridge. This shear component along with the step sense of the ridge segments may favour or oppose the curving of tip towards adjacent fracture due to local tip-induced stress. When the far-field shear stress favors the tip curvature they increase the angle at which the ridge tips curve away from the ridge plane. When it opposes, then no linkage should take place (similar to the findings of Zwaan and Schreurs 2017 for rift basins). Sharp deflection of the crack tip almost at right angle to the crack plane as observed in our experiments with $\alpha=30^{\circ}$ (figure $9 \mathrm{e}$ ) matches well with the deflection of the naturally occurring fracture in Pizzo Molare, Ticino, Switzerland (figure 31.15, Ramsay and Lisle 2000). Horn structure on dykes, e.g., as described by Ramsay and Lisle (2000; figure 31.17) is quite similar to the structure produced by curving and linkage of cracks with $\alpha=15^{\circ}$ (figure 7b).

When the ridge segments are arranged with zero (or very negligible overlap or underlap), if their tips deflect from the crack plane towards the adjacent crack at an angle greater than $45^{\circ}$ then transform like structure may be produced (as shown by our experiments with $\alpha=30^{\circ}$ ) as a continuation of ridges. This finding can be matched with the natural example from North Iceland as given by Gudmundsson et al. (1993). The axial rift of North Iceland joins mid-ocean Kolbeinsey ridge along a zone of transform fault named Tjornes fracture zone (figure 12). The angle between the strike of the axial rift zone in North Iceland and the strike of the Tjornes fracture zone transform fault, most clearly exposed by the joining of Husavik strike slip fault and Gudfinnugja normal fault, is roughly $60^{\circ}$. The direction of oblique rifting is $\mathrm{N} 73^{\circ} \mathrm{W}$ i.e., neither parallel to the trend of the Husavik fault (or the Tjornes fracture zone) nor perpendicular to the trend of the Gudfinnugja normal fault or the strike of the axial rift zone (figure 12).

When the angle of the deflection of the tip from the crack plane is less than $45^{\circ}$, initially an OSC like structure maybe produced (as shown in our experiments with $\alpha=15^{\circ}$ ), which will soon become a transfer zone by tip to wall linkage of adjacent cracks, isolating a micro-plate in between. These findings are partly in accordance of the theoretical 


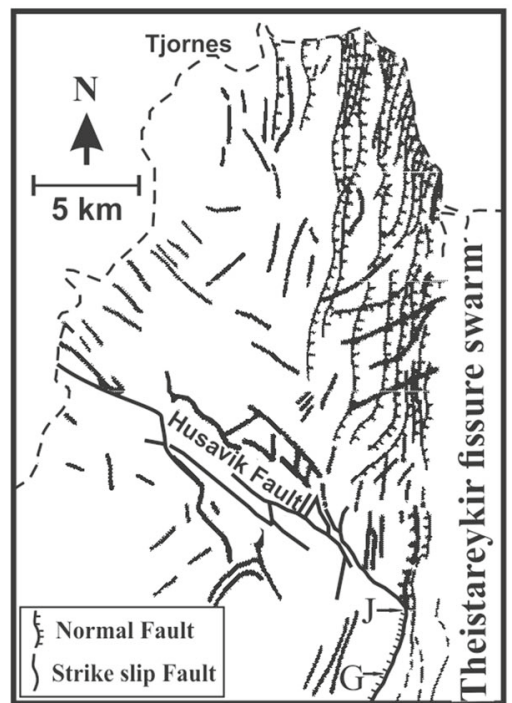

(a)

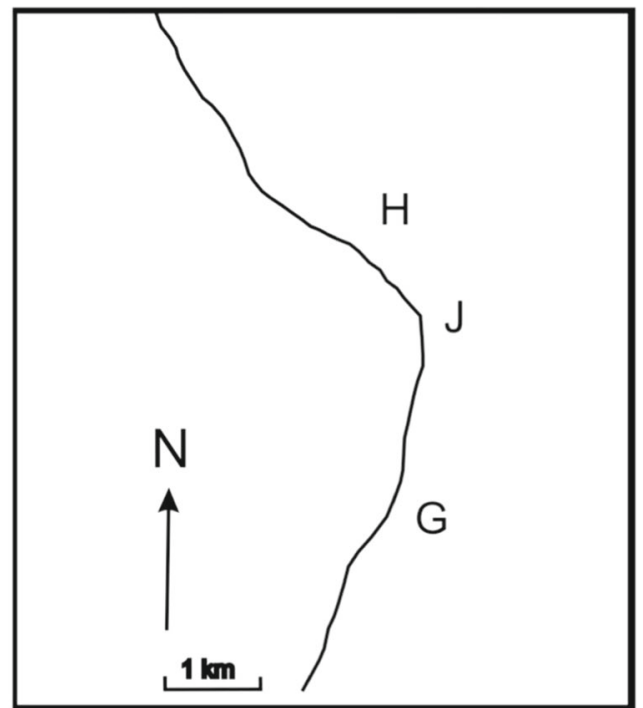

(b)

Figure 12. (a) Tectonic map of the Tjornes peninsula. The junction $(J)$ between the Husavik fault and the Gudfinnugja $(G)$ normal fault is indicated by arrow (modified after figure 2 of Gudmundsson et al. 1993). (b) Hand sketch of the aerial view of the trace of the junction between the Husavik fault $(H)$ and the Gudfinnugja normal fault $(G)$ modified after figure 7 of Gudmundsson et al. (1993).

prediction of Pollard and Aydin (1984) that OSC develop along surfaces of little or no shear stress whereas transform fault develop along surfaces of relatively higher shear stress. At the same time, in contrast to their predictions, our experimental results show that transform fault-like structures can also form as a continuation of ridges and do not always truncate the ridges.

\section{Conclusions}

The present series of experiments have shown that amount and orientation of far-field stress plays a crucial role in controlling the behavior of cracks within an array. As natural veins, dykes, initial stages of development of oceanic ridge segments and/or rift basins can also be represented as enechelon cracks; these results are applied to interpret the variation in propagation and linkage of those structures.

- For mode I loading if far-field stress dominates, cracks should propagate in straight path, initially creating an overlapping zone (geometrically similar to OSC) and finally tip to wall linkage between adjacent cracks should take place to isolate a domain (geometrically resembling a micro-plate).

- For mixed mode loading, if due to the combined effect of far-field and local stresses the tips deflects from the crack plane at less than $45^{\circ}$, initially an overlapping zone (geometrically resembling OSC like structure) may be created and finally tip to wall linkage between adjacent cracks would take place to isolate a domain (geometrically resembling a micro plate or a horn structure between dykes). If the tips deflected at an angle greater than $45^{\circ}$ then a transform fault like structure may be created due to tip to tip linkage of adjacent cracks.

- However, for mixed mode loading, if the shear component of the far-field stress is in opposite direction of the local stress, then there will be no linkage between the cracks.

\section{Acknowledgements}

The authors wish to thank the Department of Science and Technology, Government of India for the financial support required to carry out the work (DST Project No. SR/WOS-A/ES-26/2013). The working space was provided by Department of Geology, University of Delhi.

\section{References}

Acocella V 2008 Transform faults or overlapping spreading centers? Oceanic ridge interactions revealed by analogue models; Earth Planet. Sci. Lett. 265 379-385. 
Acocella V, Faccenna C, Funiciello R and Rossetti F 1999 Sand-box modeling of basement-controlled transfer zones in extensional domains; Terra Nova 11(4) 149-156.

Acocella V, Gudmundsson A and Funiciello R 2000 Interaction and linkage of extension fractures and normal faults: Examples from the rift zone of Iceland; J. Struct. Geol. 22 1233-1246.

An L J 1998 Development of fault discontinuities in shear experiments; Tectonophys. 293(1-2) 45-59.

An L J and Sammis C G 1996 Development of strike-slip faults: Shear experiments in granular materials and clay using a new technique; J. Struct. Geol. 18(8) 1061-1077.

Basile C and Brun J P 1999 Transtensional faulting patterns ranging from pull-apart basins to transform continental margins: An experimental investigation; J. Struct. Geol. 21(1) 23-37.

Bellahsen N and Daniel J M 2005 Fault reactivation control on normal fault growth: An experimental study; J. Struct. Geol. 27 769-780.

Chattopadhyay A and Mandal N 2002 Progressive changes in strain patterns and fold styles in a deforming ductile orogenic wedge: An experimental study; J. Geodyn. 33(3) 353-376.

Cotton J T and Koyi H A 2000 Modeling of thrust fronts above ductile and frictional detachments: Application to structures in the Salt Range and Potwar Plateau, Pakistan; Geol. Soc. Am. Bull. 112(3) 351-363.

Cowie P A 1998 Normal fault growth in three-dimensions in continental and oceanic crust; Faulting and magmatism at mid-ocean ridges, pp. 325-348.

Cox S J D and Scholz C H 1988 On the formation and growth of faults: An experimental study; J. Struct. Geol. 10(4) 413-430.

Crider J G 2001 Oblique slip and the geometry of normalfault linkage: Mechanics and a case study from the Basin and Range in Oregon; J. Struct. Geol. 23 1997-2009.

Du Y and Aydin A 1991 Interaction of multiple cracks and formation of echelon crack arrays; Int. J. Numer. Anal. Methods Geomech. 15 205-218.

Fleck N A 1991 Brittle fracture due to an array of microcracks; Proc. Roy. Soc. London A 432(1884) 55-76.

Ghosh N, Chakra M and Chattopadhyay A 2014 An experimental approach to strain pattern and folding in unconfined and/or partitioned transpressional deformation; Int. J. Earth Sci. 103 349-365.

Grindlay N R and Fox P J 1993 Lithospheric stresses associated with non-transform offsets of the Mid-Atlantic Ridge: Implications from a finite element analysis; Tectonics 12(4) 982-1003.

Gudmundsson A 1995 Stress fields associated with oceanic transform faults; Earth Planet. Sci. Lett. 136(3-4) 603614.

Gudmundsson A, Brynjolfsson S and Jonsson M T 1993 Structural analysis of a transform fault-rift zone junction in North Iceland; Tectonophys. 220(1-4) 205-221.

Hancock P L 1972 The analysis of en-echelon veins; Geol. Mag. 109(3) 269-276.

Hubbert M K 1937 Theory of scale models as applied to the study of geologic structures; Geol. Soc. Am. Bull. 48 1459-1520.

Jaeger J C 1969 Elasticity, fracture and flow; Methuen, London.
Katz R F, Ragnarsson R and Bodenschatz E 2005 Tectonic microplates in a wax model of sea-floor spreading; New J. Phys. 7 1-11.

Lebel D and Mountjoy E W 1995 Numerical modeling of propagation and overlap of thrust faults, with application to the thrust-fold belt of central Alberta; J. Struct. Geol. 17(5) 631-646.

Macdonald K and Fox P 1983 Overlapping spreading centers: New accretion geometry on the East Pacific Rise; Nature 302 55-58.

Macdonald K C, Fox P J, Perram L J, Eisen M F, Haymon R M, Miller S P, Carbotte S M, Cormier M H and Shor A N 1988 A new view of the mid-ocean ridge from the behavior of ridge-axis discontinuities; Nature 335(6187) 217.

Macdonald K, Sempere J C and Fox P J 1984 East Pacific Rise from Siqueiros to Orozco fracture zones: Along-strike continuity of axial neo-volcanic zone and structure and evolution of overlapping spreading centers; J. Geophys. Res. 89(B7) 6049-6069.

Maerten L, Willemse E J, Pollard D D and Rawnsley K 1999 Slip distributions on intersecting normal faults; J. Struct. Geol. 21(3) 259-272.

Mandal N 1995 Mode of development of sigmoidal enechelon fractures; Proc. Indian Acad. Sci. - Earth Planet. Sci. 104(3) 453-464.

Mauduit T and Dauteuil O 1996 Small-scale models of oceanic transform zones; J. Geophys. Res. Solid Earth 101(B9) 20195-20209.

Moir H, Lunn R J, Shipton Z K and Kirkpatrick J D 2010 Simulating brittle fault evolution from networks of preexisting joints within crystalline rock; J. Struct. Geol. 32 1742-1753.

Nelson R A, Patton T L and Morley C K 1992 Rift-segment interaction and its relation to hydrocarbon exploration in continental rift systems; AAPG Bull. 76 1153-1169.

Nicholson R and Pollard D D 1985 Dilation and linkage of echelon cracks; J. Struct. Geol. 7 583-590.

Olson J and Pollard D 1989 Inferring paleo-stresses from natural fracture patterns: A new method; Geology 17 345348.

Olson J E and Pollard D D 1991 The initiation and growth of en-echelon veins; J. Struct. Geol. 13(5) 595-608.

Pollard D D and Aydin A 1984 Propagation and linkage of oceanic ridge segments; J. Geophys. Res. 89 10017-10028.

Pollard D D, Segall P and Delaney P T 1982 Formation and interpretation of dilatant echelon cracks; Geol. Soc. Am. Bull. 93 1291-1303.

Ramberg H 1975 Particle paths, displacements and progressive strain applicable to rocks; Tectonophys. 28 1-37.

Ramsay J G and Lisle R J 2000 The techniques of modern structural geology; Applications of continuum mechanics in structural geology, Academic, San Diego, California.

Schreurs G, Hanni R and Drayer B 1999 4D analysis of analogue models: Examples of transfer zones in thrust belts; Terra Nova Abs. Supp. EGU 1011610.

Segall P and Pollard D D 1980 Mechanics of discontinuous faults; J. Geophys. Res. 85(B8) 4337-4350.

Sempere J C and Macdonald K C 1986 Overlapping spreading centers: Implications from crack growth simulation by the displacement discontinuity method; Tectonics 5(1) 151-163. 
Shemenda A I and Grokholsky A L 1991 A formation and evolution of overlapping spreading centers (constraints based on physical modelling); Tectonophys. 199 389-404.

Swain M V and Hagan J T 1978 Some observations of overlapping interacting cracks; Eng. Fract. Mech. 10 299-304.

Taylor B, Crook K and Sinton J 1994 Extensional transform zones and oblique spreading centers; J. Geophys. Res. 99(B10) 19707-19718.

Tchalenko J S 1970 Similarities between shear zones of different magnitudes; Geol. Soc. Am. Bull. 81(6) 1625-1640.

Tentler T 2003a Analogue modeling of overlapping spreading centers: Insights into their propagation and coalescence; Tectonophys. 376(1-2) 99-115.

Tentler T 2003b Analogue modeling of tension fracture pattern in relation to mid-ocean ridge propagation; Geophys. Res. Lett. 30(6) 1268.

Tentler T 2007 Focused and diffuse extension in controls of ocean ridge segmentation in analogue models; Tectonics 26 TC5008.

Tentler T and Acocella V 2010 How does the initial configuration of oceanic ridge segments affect their interaction?
Insights from analogue models; J. Geophys. Res. 115 $1-16$.

Thomas A L and Pollard D D 1993 The geometry of echelon fractures in rock: Implications from laboratory and numerical experiments; J. Struct. Geol. 15 323-334.

Willemse E J 1997 Segmented normal faults: Correspondence between three-dimensional mechanical models and field data; J. Geophys. Res. 102(B1) 675-692.

Willemse E J, Pollard D D and Aydin A 1996 Threedimensional analyses of slip distributions on normal fault arrays with consequences for fault scaling; J. Struct. Geol. 18(2-3) 295-309.

Zwaan F and Schreurs G 2017 How oblique extension and structural inheritance influence rift segment interaction: Insights from 4D analog models; Interpretation 5(1) 119 138.

Zwaan F, Schreurs G, Naliboff J and Buiter S J H 2016 Insights into the effects of oblique extension on continental rift interaction from $3 \mathrm{D}$ analogue and numerical models; Tectonophys. 693 239-260. 